\title{
Triterpenoids and Other Non-Polar Compounds in Leaves of Wild and Cultivated Vaccinium Species
}

\author{
Radka Vrancheva $^{1}\left(\mathbb{D}\right.$, Ivan Ivanov $^{2}\left(\mathbb{D}\right.$, Ivayla Dincheva ${ }^{3} \oplus$, Ilian Badjakov ${ }^{3}\left(\mathbb{D}\right.$ and Atanas Pavlov ${ }^{1,4, *}$ \\ 1 Department of Analytical Chemistry and Physical Chemistry, University of Food Technologies, \\ 26 Maritza Blvd., 4002 Plovdiv, Bulgaria; radka_vrancheva@yahoo.com \\ 2 Department of Organic Chemistry and Inorganic Chemistry, University of Food Technologies, \\ 26 Maritza Blvd., 4002 Plovdiv, Bulgaria; ivanov_ivan.1979@yahoo.com \\ 3 AgroBioInstitute, Agricultural Academy, 8 Dr. Tsankov Blvd., 1164 Sofia, Bulgaria; \\ ivadincheva@yahoo.com (I.D.); ibadjakov@gmail.com (I.B.) \\ 4 Laboratory of Cell Biosystems, Department of Biotechnology, The Stephan Angeloff Institute of Microbiology, \\ Bulgarian Academy of Sciences, 139 Ruski Blvd., 4000 Plovdiv, Bulgaria \\ * Correspondence: at_pavlov@yahoo.com; Tel.: +359-8986-90599
}

Citation: Vrancheva, R.; Ivanov, I.; Dincheva, I.; Badjakov, I.; Pavlov, A Triterpenoids and Other Non-Polar Compounds in Leaves of Wild and Cultivated Vaccinium Species. Plants 2021, 10, 94. https://doi.org/ $10.3390 /$ plants10010094

Received: 17 December 2020

Accepted: 2 January 2021

Published: 5 January 2021

Publisher's Note: MDPI stays neutral with regard to jurisdictional clai$\mathrm{ms}$ in published maps and institutional affiliations.

Copyright: (C) 2021 by the authors. Licensee MDPI, Basel, Switzerland. This article is an open access article distributed under the terms and conditions of the Creative Commons Attribution (CC BY) license (https:// creativecommons.org/licenses/by/ $4.0 /)$.

\begin{abstract}
The purpose of the current study was to identify and quantify triterpenoids and other nonpolar compounds in the leaves of three high bush blueberry cultivars (Vaccinium corymbosum L. var. Bluegold, var. Bluecrop and var. Elliott) and three natural populations of Vaccinium species (Vaccinium uliginosum L., Vaccinium myrtillus L. and Vaccinium vitis-idaea L.) by means of gas chromatography mass spectrometry (GC-MS) and high-performance liquid chromatography with diode array detector (HPLC-DAD). Metabolite profiles differed significantly among the Vaccinium species analyzed, as well as among the populations of the same species. The populations of $V$. vitis-idaea predominantly contained relative concentrations of phytosterols (varying between $10.48 \%$ of total ion current (TIC) and $22.29 \%$ of TIC) and almost twice the content of triterpenes (from $29.84 \%$ of TIC to $49.62 \%$ of TIC) of the other berry species investigated. The leaves of $V$. corymbosum varieties biosynthesized the highest relative amount of fatty acids, while the leaves of the populations of $V$. uliginosum had the highest relative concentrations of fatty alcohols. The results of principal component analysis (PCA) and hierarchical cluster analysis (HCA) showed that the diverse populations of each berry species analyzed differed from each other, most likely due to variations in the climatic and geographical conditions of their localities.
\end{abstract}

Keywords: Vaccinium corymbosum L.; Vaccinium uliginosum L.; Vaccinium myrtillus L.; Vaccinium vitis-idaea L.; GC-MS; HPLC; triterpenes; phytosterols; principal component analysis; hierarchical cluster analysis

\section{Introduction}

In recent years, edible berries of the genus Vaccinium (Ericaceae family) have been among the most important berry species for the food and pharmaceutical industries due to their delicious taste and high content of valuable bioactive substances. The genus contains economically important, cultivated and wild berry species, such as blueberries (e.g., Vaccinium corymbosum L. (highbush blueberry), Vaccinium uliginosum L. (bog blueberry)), bilberry (Vaccinium myrtillus L.), and lingonberry (Vaccinium vitis-idaea L., also known as cowberry) [1].

$V$. myrtillus, $V$. vitis-idaea and $V$. uliginosum are mostly collected from their natural habitats [2-4]. These plant species are of significant economic importance because of the application of their fruits, and sometimes leaves, in the production of various foods, pharmaceuticals, cosmetics, and health-care products. V. myrtillus is a perennial, wild and small deciduous shrub that grows in the mountains and forests of Europe [5]. Bilberry has been used since the Middle Ages as an antidiabetic, astringent, antiseptic, and antidiarrheal 
agent [6]. Crude bilberry fruit extracts are now marketed as pharmaceutical preparations for the treatment of ophthalmological diseases and blood vessel disorders [7]. In European countries, bilberry leaf extracts have traditionally been used as herbal medicines for the urinary tract due to their astringent and antiseptic properties. They also possess antibacterial, anti-inflammatory, hypoglycemic, lipid-lowering and hypolipidemic activities [8,9]. These health benefits are mostly attributed to the various phenolic compounds, such as anthocyanins and phenolic acids $[5,10,11]$. However, other valuable compounds, such as stilbenes, iridoid glycosides, fatty acids, vitamins, minerals, and dietary fibers have also been found in bilberry leaves [12,13]. The stems and rhizomes of this species are still not well studied organs but they also contain phenolics with various biological activities [3].

$V$. vitis-idaea is a small evergreen shrub. Lingonberry plants are extremely hardy, tolerating $40{ }^{\circ} \mathrm{C}$ or lower temperatures, with diverse habitats ranging from lowland to upland and mountain areas, and prefer acid soils [5]. The fruits and leaves of this species also contain a wide range of biologically active compounds: anthocyanins, flavanoids, phenolic acids, chromones, coumarins, lignans, sterols, triterpenoids, fatty acids, minerals $(\mathrm{Mg}$, $\mathrm{K}, \mathrm{Fe}, \mathrm{Cr}, \mathrm{Cu}$ and $\mathrm{Zn}$ ), responsible for their antitussive, anti-inflammatory, anti-catarrhal, and neuroprotective effect in vitro [14-16]. Moreover, cowberry fruits and leaves have a well-established role in pharmacognosy and are used in herbal medicine for treatment of urinary- and digestive-tract infections [17]. These studies indicate that the leaves of bilberry and lingonberry are potential raw materials for functional foods.

V. uliginosum is a small shrub native to some regions of the Northern Hemisphere, especially at high altitudes, in zones of Europe, Asia and North America. It is an Arctic and boreal circumpolar species, growing on wet acidic soils [5]. While the chemical composition of the fruits of this species (polyphenols, lipids, organic acids, aromatic compounds, mineral elements, vitamins, amino acids and others) have been widely investigated [4,18], studies on its leaf constituents are scanty [5].

$V$. corymbosum var. Bluecrop is a cultivar obtained from four varieties of V. corymbosum. The fruits of this plant are widely used especially by the food industry, hence their welldefined chemical constitution (anthocyanins, vitamins (B1, B2, PP, C, A), minerals (Ca, P, Fe) [19].

Although the number of identified phytochemicals in blueberries, bilberry and lingonberry is growing, there is still scanty information regarding their terpenoid content in leaves $[2,3,19]$. Terpenoids are widely distributed plant secondary metabolites with distinct chemical structures. They produce various aromas and participate in plant defense and pollination [20]. The numerous valuable biological activities (anti-inflammatory, antiulcer, antimicrobial, hepatoprotective, immunomodulatory, hypolipidemic, cholesterol-lowering, antiatherosclerotic, anticarcinogenic, etc.) of these compounds have led to a growing interest in their potential applications in the pharmaceutical, cosmetic and food industries [2]. Thus, there is an increasing demand for naturally occurring triterpenoids, especially for edible and medicinal plants.

Plants are influenced by many abiotic and biotic factors that are a possible reason for the chemodiversity observed among plants of the same species growing in different geoclimates. While the Vaccinium fruits have a seasonal nature that implies high harvesting and storage costs, the leaves are available in most seasons and some even in wintertime (e.g., lingonberry and bear berry) [5]. Therefore, the purpose of the current study was to investigate triterpenoids and other non-polar compounds in the leaves of highbush blueberry cultivars (Vaccinium corymbosum L. var. Bluegold, var. Bluecrop and var. Elliott), wild bog blueberries (Vaccinium uliginosum L.), wild bilberries (Vaccinium myrtillus L.), and wild lingonberries (Vaccinium vitis-idaea L.) by means of gas chromatography mass spectrometry (GC-MS) and high-performance liquid chromatography with diode array detector (HPLC-DAD), as well as to confirm sample differences or similarities by suitable chemometric analyses, such as principal component analysis (PCA) and hierarchical cluster analysis (HCA). 


\section{Results}

2.1. Gas Chromatography Mass Spectrometry (GC-MS) Profiling of Non-Polar Compounds in the Leaves of Berry Species

A total of 49 compounds, including hydrocarbons, fatty acids, fatty alcohols, phytosterols and triterpenes, were identified in three wild Vaccinium species (V. uliginosum, $V$. myrtillus and $V$. vitis-idaea) and three cultivated varieties of $V$. corymbosum using GC-MS (Table 1).

GC-MS analysis of the $n$-hexane extracts obtained from the leaves of the three V. corymbosum cultivars (var. Bluegold, var. Bluecrop and var. Elliot) revealed the presence of 38 phytoconstituents, classified into five categories: hydrocarbons, fatty acids, fatty alcohols, phytosterols, and triterpenes. The species demonstrated high relative content of fatty acids in its leaves (57.5\% to $64.4 \%$ of total ion current (TIC)), 17 representatives of which were identified (C8 to C26). The most abundant saturated fatty acids (SFA) were palmitic acid C16:0 (9\% to $11 \%$ of TIC), followed by arachidic acid C20:0 (3\% to $4 \%$ of TIC). The main polyunsaturated fatty acids (PUFA) were $\alpha$-linolenic acid C18:3 (29\% to $34 \%$ of TIC) and linoleic acid C18:2 (9\% to 9.7\% of TIC) in all analyzed varieties. The PUFA content ranged from $39 \%$ to $43 \%$ of TIC, but the saturated fatty acids (SFA) were from $18 \%$ to $20 \%$ of TIC. In the leaf extracts of $V$. corymbosum (var. Bluegold, var. Bluecrop and var. Elliot), margaric acid C17:0 was not identified. The relative amount of fatty alcohols was from $11 \%$ to $12.5 \%$ of TIC, with nine representatives identified (C8 to $\mathrm{C} 28$ ). The major fatty alcohols were the diterpene alcohol, phytol C20 5.6\% to $6.7 \%$ of TIC), followed by ceryl alcohol C26 (1.1\% to $1.8 \%$ of TIC).

Important groups of compounds identified as part of the berry lipids are triterpenes and sterols. Triterpenes were found to compose from $13.0 \%$ to $22.6 \%$ of the total identified compounds in the leaves of the $V$. corymbosum varieties, while the content of phytosterols varied between $7.3 \%$ and $11.0 \%$ of TIC. The major phytosterol in the studied berries was $\beta$-sitosterol (5.1\% to $7.1 \%$ of TIC) and the main triterpenes were ursolic acid acetate $(4.4 \%$ to $12 \%$ of TIC), followed by oleanolic acid acetate (3.4\% to $6.1 \%$ of TIC) and lanosterol ( $1.2 \%$ to $2.2 \%$ of TIC).

GC-MS analysis of the nonpolar extracts obtained from the leaves of three wild populations of V. uliginosum (locality Beklemeto, the Balkan Mountains; locality Mount Golyam Perelik, the Rhodope Mountains, and locality Cherni Vrah, Vitosha Mountain) are summarized in Table 1 . The populations from the three locations demonstrated high relative content of fatty acids in their leaves (43.1\% of TIC to $52.3 \%$ of TIC), with 13 representatives identified (from C12 to C26). The main representative of PUFA was $\alpha$ linolenic acid C18:3 (10.7\% to $16 \%$ of TIC), while the most abundant SFA was palmitic acid C16:0 (9.4\% to $13.8 \%$ of TIC), followed by arachidic acid C20:0 (7\% to $9 \%$ of TIC). The major phytosterol in the populations of $V$. uliginosum was $\beta$-sitosterol (7\% to $9 \%$ of TIC). Ursolic acid acetate (from $6 \%$ to $11.8 \%$ of TIC) and oleanolic acid acetate (3.3\% to $4 \%$ of TIC) were the main triterpenes identified. The leaves of population Vu3 from locality Mount Perelik (the Rhodope Mountains) possessed the highest amount of phytosterols and triterpenes compared to the other two populations. 
Table 1. Identified phytocompounds in Vaccinium spp. analysed by gas chromatography mass spectrometry (GC-MS). The results are given as \% of total ion current *

\begin{tabular}{|c|c|c|c|c|c|c|c|c|c|c|c|c|c|c|c|c|c|c|c|c|}
\hline \multirow{2}{*}{ No. } & \multirow{2}{*}{ RI } & \multirow{2}{*}{ Compounds } & \multicolumn{3}{|c|}{ V. Corymbosum } & \multicolumn{3}{|c|}{ V. Uliginosum } & \multicolumn{5}{|c|}{ V.Myrtillus } & \multicolumn{7}{|c|}{ V. Vitis-idaea } \\
\hline & & & Vc1 & Vc2 & Vc3 & Vu1 & $\mathrm{Vu} 2$ & Vu3 & Vm1 & $\mathrm{Vm} 2$ & $\mathrm{Vm} 3$ & $\mathrm{Vm} 4$ & Vm5 & Vi1 & Vi2 & Vi3 & Vi4 & Vi5 & Vi6 & Vi7 \\
\hline \multicolumn{21}{|c|}{ Hydrocarbons } \\
\hline 1 & 1200 & $n$-Dodecane & 0.12 & 0.11 & 0.10 & 0.14 & 0.21 & 0.27 & 0.32 & 0.23 & 0.17 & 0.19 & 0.12 & 0.12 & 0.20 & 0.13 & 0.15 & 0.07 & 0.12 & 0.15 \\
\hline 2 & 3100 & $n$-Hentriacontane & 0.11 & 0.12 & 0.21 & 0.21 & 0.59 & 0.25 & 0.42 & 0.71 & 0.66 & 0.24 & 0.78 & 0.41 & 0.25 & 0.34 & 0.12 & 0.14 & 0.24 & 0.32 \\
\hline \multicolumn{21}{|c|}{ Fatty alcohols } \\
\hline 3 & 1100 & n-Octanol & 0.56 & 0.80 & 0.64 & 1.15 & 0.85 & 1.04 & 0.80 & 0.61 & 0.57 & 2.54 & 4.67 & 4.42 & 8.94 & 7.85 & 7.74 & 6.69 & 6.48 & 7.94 \\
\hline 4 & 1308 & 2-Hendecanone & 0.30 & 0.14 & 0.19 & $\mathrm{nd}^{* *}$ & nd & nd & nd & nd & nd & nd & nd & nd & nd & nd & nd & nd & nd & nd \\
\hline 5 & 1484 & 2-Tridecanone & nd & nd & nd & 0.88 & 0.62 & 0.62 & nd & nd & nd & nd & nd & nd & nd & nd & nd & nd & nd & nd \\
\hline 6 & 2152 & 1-Octadecanol & nd & nd & nd & 4.53 & 4.22 & 3.85 & 0.16 & 0.43 & 0.41 & 0.20 & 0.26 & 0.11 & 0.16 & 0.21 & 0.24 & 0.16 & 0.09 & 0.16 \\
\hline 7 & 2163 & Phytol & 5.96 & 5.65 & 6.71 & 11.74 & 7.63 & 7.84 & 11.34 & 8.67 & 13.29 & 6.85 & 11.61 & 6.26 & 5.40 & 7.89 & 7.55 & 5.83 & 4.89 & 6.72 \\
\hline 8 & 2287 & Phytol isomer & nd & nd & nd & 0.20 & 0.38 & 0.33 & 2.93 & 1.30 & 0.44 & 1.37 & 2.67 & 0.23 & 1.11 & 0.51 & 0.93 & 1.34 & 0.12 & 0.25 \\
\hline 9 & 2314 & $n$-Eicosanol & 0.10 & 0.14 & 0.10 & 1.20 & 1.00 & 0.74 & nd & nd & nd & nd & nd & nd & nd & nd & nd & nd & nd & nd \\
\hline 10 & 2409 & n-Heneicosanol & 1.60 & 1.25 & 0.82 & 0.40 & 5.20 & 4.01 & nd & nd & nd & nd & nd & 2.55 & 1.52 & 0.92 & 1.74 & 0.67 & 1.52 & 1.80 \\
\hline 11 & 2545 & Behenic alcohol & 0.42 & 0.32 & 0.15 & 0.88 & 0.84 & 0.60 & 0.71 & 0.70 & 1.88 & 1.10 & 0.86 & 0.33 & 0.34 & 0.29 & 0.41 & 0.31 & 0.23 & 0.29 \\
\hline 12 & 2741 & $n$-Tetracosanol & 0.77 & 0.57 & 0.60 & 1.13 & 0.81 & 0.63 & 1.08 & 1.61 & 3.75 & 3.72 & 1.52 & 0.20 & 0.25 & 0.12 & 0.16 & 0.24 & 0.15 & 0.14 \\
\hline 13 & 2936 & Ceryl alcohol & 1.84 & 1.42 & 1.09 & 0.66 & 0.69 & 0.53 & 0.61 & 1.07 & 2.34 & 2.71 & 0.98 & 0.24 & 0.20 & 0.11 & 0.18 & 0.11 & 0.19 & 0.22 \\
\hline 14 & 3134 & Octacosyl alcohol & 0.92 & 1.03 & 0.72 & 0.41 & 0.42 & 0.38 & 0.25 & 0.40 & 0.82 & 0.84 & 0.47 & 0.17 & 0.22 & 0.11 & 0.16 & 0.13 & 0.15 & 0.26 \\
\hline \multicolumn{21}{|c|}{ Phenolic acids } \\
\hline 15 & 1524 & 4-methoxy-Benzoic acid & nd & nd & nd & nd & nd & nd & 0.19 & 0.15 & 0.13 & 0.10 & 0.12 & nd & nd & nd & nd & nd & nd & nd \\
\hline 16 & 1231 & Benzoic acid & nd & nd & nd & nd & nd & nd & 0.25 & 0.22 & 0.09 & 0.12 & 0.17 & 0.68 & 1.23 & 0.40 & 0.14 & 0.15 & 0.08 & 0.10 \\
\hline 17 & 1830 & 4-methoxy-Cinnamic acid & 0.12 & 0.08 & 0.11 & nd & nd & nd & 0.51 & 0.13 & 0.19 & 0.18 & 0.46 & 0.14 & 0.12 & 0.09 & 0.23 & 0.23 & 0.27 & 0.23 \\
\hline 18 & 1259 & Caprylic acid & nd & nd & nd & nd & nd & nd & 0.15 & 0.11 & 0.12 & 0.16 & 0.11 & 0.23 & 0.10 & 0.18 & 0.12 & 0.18 & 0.12 & 0.12 \\
\hline 19 & 1446 & Capric acid & 2.03 & 1.02 & 0.46 & nd & nd & nd & 0.14 & 0.10 & 0.20 & 0.10 & 0.16 & nd & nd & nd & nd & nd & nd & nd \\
\hline 20 & 1652 & Lauric acid & 0.33 & 0.28 & 0.19 & 1.27 & 3.18 & 3.75 & 0.63 & 0.56 & 0.26 & 0.28 & 0.25 & 0.48 & 0.46 & 0.45 & 0.52 & 0.41 & 0.46 & 0.47 \\
\hline 21 & 1848 & Myristic acid & 0.70 & 0.51 & 0.55 & 1.00 & 1.87 & 2.28 & 1.68 & 1.02 & 0.86 & 0.64 & 0.66 & 1.05 & 1.05 & 1.15 & 1.25 & 1.07 & 1.22 & 1.14 \\
\hline 22 & 2017 & Palmitoleic acid & 0.07 & 0.25 & 0.12 & nd & nd & nd & 0.38 & 0.11 & 0.47 & 0.14 & 0.31 & 0.15 & 0.08 & 0.36 & 0.30 & 0.19 & 0.47 & 0.28 \\
\hline 23 & 2026 & Palmitelaidic acid & 0.61 & 0.60 & 0.53 & 0.20 & 0.47 & 0.32 & 0.66 & 0.62 & 0.51 & 0.40 & 0.63 & 0.25 & 0.15 & 0.17 & 0.17 & 0.14 & 0.13 & 0.26 \\
\hline 24 & 2039 & Palmitic acid & 9.44 & 10.94 & 8.92 & 9.35 & 11.44 & 13.79 & 11.84 & 12.79 & 9.46 & 10.65 & 12.18 & 9.70 & 10.33 & 9.35 & 11.36 & 8.21 & 9.48 & 10.97 \\
\hline 25 & 2141 & Margaric acid & nd & nd & nd & 0.14 & 0.19 & 0.22 & 0.17 & 0.16 & 0.15 & 0.12 & 0.17 & 0.14 & 0.10 & 0.19 & 0.26 & 0.12 & 0.18 & 0.16 \\
\hline 26 & 2205 & Linoleic acid & 9.14 & 8.94 & 9.68 & 2.77 & 4.23 & 3.92 & 3.90 & 7.21 & 4.01 & 7.34 & 5.60 & 4.04 & 2.67 & 3.36 & 3.06 & 2.08 & 3.37 & 3.74 \\
\hline 27 & 2209 & Oleic acid & 0.22 & 0.17 & 0.32 & 0.74 & 0.35 & 0.49 & 0.46 & 0.23 & 0.76 & 0.25 & 0.51 & 0.61 & 0.36 & 0.23 & 0.32 & 1.60 & 0.78 & 0.49 \\
\hline 28 & 2218 & $\alpha$-Linolenic acid & 34.09 & 30.45 & 29.12 & 10.68 & 16.03 & 12.11 & 12.89 & 22.25 & 13.00 & 16.70 & 22.62 & 10.00 & 6.09 & 7.74 & 8.00 & 5.03 & 6.84 & 10.68 \\
\hline 29 & 2240 & Stearic acid & 1.53 & 1.43 & 1.57 & 2.05 & 2.36 & 2.69 & 1.95 & 1.91 & 2.54 & 2.20 & 1.87 & 1.60 & 2.11 & 2.29 & 2.07 & 1.81 & 2.10 & 1.93 \\
\hline 30 & 2436 & Arachidic acid & 4.10 & 2.71 & 3.61 & 8.93 & 6.99 & 8.21 & 1.65 & 2.26 & 1.13 & 1.08 & 1.02 & 0.56 & 0.78 & 0.69 & 0.74 & 0.91 & 1.05 & 0.64 \\
\hline 31 & 2637 & Behenic acid & 0.27 & 0.39 & 0.29 & 1.42 & 1.03 & 1.18 & 0.83 & 0.78 & 1.18 & 1.04 & 0.77 & 0.23 & 0.27 & 0.17 & 0.24 & 0.27 & 0.29 & 0.26 \\
\hline 32 & 2833 & Lignoceric acid & 0.85 & 1.13 & 0.93 & 1.86 & 1.45 & 1.31 & 1.10 & 1.35 & 2.96 & 1.91 & 1.61 & 0.22 & 0.23 & 0.18 & 0.26 & 0.19 & 0.29 & 0.23 \\
\hline 33 & 2928 & Pentacosylic acid & nd & nd & nd & nd & nd & nd & 0.27 & 0.50 & 0.58 & 0.56 & 0.37 & 0.14 & 0.09 & 0.24 & 0.21 & 0.11 & 0.26 & 0.28 \\
\hline \multirow[t]{2}{*}{34} & 3032 & Cerotic acid & 1.05 & 1.38 & 1.20 & 2.72 & 2.53 & 2.10 & 0.82 & 1.48 & 2.21 & 1.18 & 1.26 & 0.18 & 0.18 & 0.21 & 0.27 & 0.18 & 0.23 & 0.16 \\
\hline & & \multicolumn{19}{|c|}{ Phytosterols } \\
\hline 35 & 3261 & Campesterol & 0.21 & 0.52 & 0.29 & 0.76 & 0.94 & 1.20 & 0.22 & 1.16 & 1.25 & 0.71 & 0.80 & 0.41 & 0.54 & 0.23 & 0.33 & 0.19 & 0.22 & 0.17 \\
\hline 36 & 3279 & Stigmasterol & nd & nd & nd & nd & nd & nd & 0.31 & 0.19 & 0.27 & 0.15 & 0.19 & nd & nd & nd & nd & nd & nd & nd \\
\hline
\end{tabular}


Table 1. Cont.

\begin{tabular}{|c|c|c|c|c|c|c|c|c|c|c|c|c|c|c|c|c|c|c|c|c|}
\hline \multirow{2}{*}{ No. } & \multirow{2}{*}{ RI } & \multirow{2}{*}{ Compounds } & \multicolumn{3}{|c|}{ V. Corymbosum } & \multicolumn{3}{|c|}{ V. Uliginosum } & \multicolumn{5}{|c|}{ V.Myrtillus } & \multicolumn{7}{|c|}{ V. Vitis-idaea } \\
\hline & & & Vc1 & Vc2 & Vc3 & Vu1 & $\mathrm{Vu} 2$ & Vu3 & Vm1 & Vm2 & Vm3 & Vm4 & Vm5 & Vi1 & Vi2 & Vi3 & Vi4 & Vi5 & Vi6 & Vi7 \\
\hline 37 & 3302 & $\beta$-Sitosterol & 5.98 & 7.15 & 5.16 & 7.99 & 7.00 & 9.05 & 8.94 & 6.78 & 12.63 & 15.51 & 9.59 & 6.28 & 6.88 & 5.43 & 4.84 & 4.15 & 6.59 & 5.35 \\
\hline 38 & 3314 & Stigmastanol & 0.55 & 0.75 & 0.45 & 0.58 & 0.41 & 0.56 & 0.47 & 0.37 & 0.49 & 0.51 & 0.40 & 0.34 & 0.24 & 0.61 & 2.03 & 0.45 & 0.61 & 0.34 \\
\hline 39 & 3318 & Cycloartenol & nd & nd & nd & 0.70 & 0.43 & 0.38 & nd & nd & nd & nd & nd & nd & nd & nd & nd & nd & nd & nd \\
\hline 40 & 3403 & Lanosterol & 1.43 & 2.19 & 1.20 & 2.14 & 0.77 & 0.62 & 0.46 & 0.23 & 0.33 & 0.59 & 0.21 & 3.20 & 4.80 & 4.32 & 2.81 & 4.96 & 3.44 & 3.36 \\
\hline \multirow[t]{2}{*}{41} & 3416 & Cycloartenyl acetate & 0.26 & 0.44 & 0.15 & 0.42 & 0.45 & 0.44 & 1.74 & 0.58 & 0.47 & 0.30 & 0.21 & 4.18 & 5.24 & 11.69 & 8.93 & 0.73 & 3.60 & 4.21 \\
\hline & \multicolumn{20}{|c|}{ Triterpenes } \\
\hline 42 & 2809 & Squalene & 0.25 & 0.43 & 0.37 & nd & nd & nd & $1.67^{\mathrm{x}} \mathrm{x} \mathrm{x}$ & 0.56 & 0.48 & 1.17 & 0.22 & 0.28 & 0.97 & 0.29 & 0.54 & 1.02 & 1.29 & 0.35 \\
\hline 43 & 3327 & $\beta$-Amyrin & 1.36 & 0.43 & 1.14 & 0.45 & 0.38 & 0.96 & 11.80 & 7.55 & 2.00 & 2.45 & 2.38 & 10.03 & 3.12 & 2.61 & 3.89 & 6.74 & 4.40 & 10.76 \\
\hline 44 & 3351 & $\alpha$-Amyrin + Lupeol & 3.18 & 2.16 & 2.54 & 0.98 & 0.29 & 0.61 & 6.25 & 5.41 & 1.23 & 0.84 & 2.11 & 9.48 & 11.18 & 8.79 & 5.91 & 12.25 & 14.81 & 9.24 \\
\hline 45 & 3440 & Lupenyl acetate & 0.25 & 0.17 & 0.21 & 0.26 & 0.41 & 0.25 & 0.26 & 1.07 & 0.45 & 0.52 & 0.31 & 0.16 & 0.40 & 0.77 & 0.34 & 0.72 & 0.67 & 0.44 \\
\hline 46 & 3455 & Betulin & 0.16 & 0.2 & 0.28 & 0.51 & 0.31 & 0.42 & 1.62 & 0.46 & 0.79 & 0.61 & 0.25 & 6.58 & 4.16 & 1.56 & 3.91 & 7.38 & 9.91 & 4.87 \\
\hline 47 & 3482 & Lupadienol acetate & nd & nd & nd & nd & nd & nd & 0.72 & 0.29 & 0.92 & 0.14 & 0.25 & 3.27 & 2.91 & 0.71 & 1.57 & 2.91 & 1.95 & 3.65 \\
\hline 48 & 3502 & Oleanolic acid acetate & 3.40 & 4.43 & 6.15 & 3.99 & 3.87 & 3.28 & 2.90 & 2.54 & 6.33 & 6.05 & 3.92 & 3.20 & 3.66 & 3.33 & 3.05 & 3.78 & 2.14 & 1.85 \\
\hline 49 & 3625 & Ursolic acid acetate & 4.39 & 7.87 & 11.96 & 11.78 & 6.91 & 5.90 & 2.01 & 1.87 & 5.27 & 3.38 & 2.73 & 4.73 & 9.31 & 11.76 & 11.38 & 14.82 & 6.53 & 3.50 \\
\hline \multicolumn{3}{|c|}{ Total identified compounds } & 98.68 & 98.58 & 98.83 & 97.22 & 97.75 & 97.13 & 98.46 & 98.70 & 98.09 & 97.86 & 98.34 & 97.90 & 98.38 & 98.06 & 98.41 & 98.66 & 97.96 & 98.48 \\
\hline
\end{tabular}

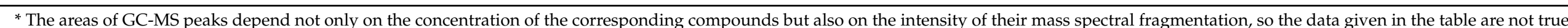
quantification but can be used for comparison of the samples, which was the object of this work; ${ }^{* *}$ nd—not detected. 
GC-MS based analysis of $n$-hexane leaf extracts of the wild $V$. myrtillus populations revealed the presence of 45 metabolites of different chemical classes (Table 1). Fatty acids were the main nonpolar compounds (between $39.53 \%$ of TIC and $53.42 \%$ of TIC) in all bilberry samples, the ratio between the PUFA and SFA being in the range of $0.77(\mathrm{Vm} 3)$ and $1.36(\mathrm{Vm} 5)$. The relative concentrations of $\alpha$-linolenic acid were the highest (between $12.89 \%$ of TIC (Vm1) and $22.6 \%$ of TIC (Vm5)) of the PUFA identified, the main SFA being palmitic acid (9.46-12.79\% of TIC). The relative quantities of triterpenes were between $12.18 \%$ of TIC (Vm5) and $27.24 \%$ of TIC (Vm1), with domination of $\beta$-amyrin, $\alpha$-amyrin + lupeol, oleanolic acid and ursolic acid. Due to the coelution of $\alpha$-amyrin and lupeol, their relative amounts were calculated together. The fatty alcohols were in the range of $14.48 \%$ of TIC (Vm2) and $23.50 \%$ of TIC (Vm3), with phytol being the principal fatty alcohol in all bilberry populations. Phytosterols represented between $9.31 \%$ of TIC (Vm2) and $17.78 \%$ of TIC (Vm4), with domination of $\beta$-sitosterol in all samples of $V$. myrtillus. Hydrocarbons (between $0.42 \%$ of TIC (Vm 4 ) and $0.94 \%$ of TIC (Vm2)) and phenolic acids (between $0.41-0.95 \%$ of $\mathrm{TIC}$ ) were found to be in minor relative concentrations compared to the other compounds identified.

The nonpolar extracts of the leaves of the wild-growing populations of $V$. vitis-idaea consisted of 43 metabolites grouped in diverse chemical classes with domination of triterpenes (29.8449.62\% of TIC). The major triterpenes in all lingonberry populations were $\beta$-amyrin, $\alpha$-amyrin + lupeol, oleanolic acid, and ursolic acid. The relative quantities of fatty alcohols were in the range of $13.82 \%$ of TIC (Vi6) and $19.11 \%$ of TIC (Vi4), with phytol being the principal fatty alcohol in all lingonberry samples. Fatty acids represented between $22.50 \%$ of TIC (Vi5) and $31.81 \%$ of TIC (Vi7) of all non-polar compounds dominated by $\alpha$-linolenic acid (5.03 to $10.68 \%$ of TIC) and palmitic acid (8.21 to $11.36 \%$ of TIC). The PUFA:SFA ratio was between 0.52 (Vi5) and 0.92 (Vi1). Phytosterols varied in the range of $10.48 \%$ of TIC (Vi5) and $22.29 \%$ of TIC (Vi3), with the domination of $\beta$-sitosterol (between $4.15 \%$ of TIC and $6.88 \%$ of TIC), lanosterol (between $2.81 \%$ of TIC and $4.96 \%$ of TIC), and cycloartenyl acetate (between $0.73 \%$ of TIC and $11.69 \%$ of TIC). The relative concentrations of hydrocarbons (between $0.21 \%$ of TIC and $0.90 \%$ of TIC) and phenolic acids (between $0.33 \%$ of TIC and $1.35 \%$ of TIC) were found to be the lowest compared to the other identified metabolites.

According to the GC-MS data, the metabolite profiles differed significantly among the Vaccinium species, as well as among the populations of the same species naturally growing in different environmental conditions (Tables 1 and 2). Among the species investigated, the leaves of $V$. corymbosum varieties biosynthesized the highest relative amount of fatty acids with prevailing quantity of PUFA, while the leaves of wild-growing populations of $V$. uliginosum had the highest relative concentrations of fatty alcohols and SFA. The leaves of $V$. myrtillus contained the highest relative quantity of hydrocarbons and MUFA, the populations of $V$. vitis-idaea having predominantly relative concentrations of phytosterols and almost twice as much triterpenes as the other berry species. The fatty alcohol 2-hendecanone was identified only in the leaves of the three V. corymbosum varieties, 2tridecanone being present only in the leaves of $V$. uliginosum populations. $n$-Eicosanol was found only in the leaves of $V$. corymbosum and $V$. uliginosum populations. Only the populations of $V$. myrtillus accumulated stigmasterol in their leaves, with the steroid precursor cycloartenol (0.4-0.7\% of TIC) found only in the samples of V. uliginosum. Capric acid was absent in the leaves of $V$. corymbosum and V. myrtillus, and palmitoleic acid and sqalene were not found only in the $V$. uliginosum populations. The leaf extracts of $V$. corymbosum varieties, $V$. myrtillus and $V$. vitis-idaea also contained low relative concentrations of some phenolic acids, most likely released after alkaline hydrolysis was applied. 
Table 2. Average relative content of chemical classes of compounds identified in Vaccinium spp. The results are presented as means \pm standard deviation.

\begin{tabular}{ccccc}
\hline Chemical Class & V. Corymbosum & V. Uliginosum & V. Myrtillus & V. Vitis-Idaea \\
\hline Hydrocarbons & $0.26 \pm 0.05$ & $0.55 \pm 0.23$ & $0.77 \pm 0.21$ & $0.40 \pm 0.12$ \\
Fatty alcohols & $11.60 \pm 0.77$ & $22.15 \pm 1.38$ & $19.71 \pm 3.65$ & $16.69 \pm 2.06$ \\
Fatty acids & $60.70 \pm 3.50$ & $49.21 \pm 5.26$ & $45.64 \pm 6.04$ & $27.48 \pm 3.08$ \\
MUFA & $0.81 \pm 0.05$ & $0.86 \pm 0.07$ & $1.00 \pm 0.25$ & $0.81 \pm 0.46$ \\
PUFA & $40.48 \pm 2.41$ & $16.58 \pm 3.43$ & $23.10 \pm 1.20$ & $10.96 \pm 2.64$ \\
SFA & $19.41 \pm 1.37$ & $31.76 \pm 3.45$ & $21.53 \pm 0.28$ & $15.71 \pm 1.29$ \\
PUFA:SFA (P:S) ratio & $2.09 \pm 0.11$ & $0.52 \pm 0.11$ & $1.08 \pm 0.28$ & $0.70 \pm 0.16$ \\
Phenolic acids & $0.10 \pm 0.02$ & nd $*$ & $0.60 \pm 0.24$ & $0.70 \pm 0.38$ \\
Phytosterols & $8.92 \pm 1.95$ & $11.61 \pm 1.40$ & $13.21 \pm 3.38$ & $15.96 \pm 3.94$ \\
Triterpenes & $17.11 \pm 4.99$ & $13.85 \pm 3.58$ & $18.36 \pm 5.70$ & $37.16 \pm 6.85$ \\
\hline
\end{tabular}

${ }^{*}$ nd-not detected: MUFA—-monounsaturated fatty acids; PUFA—polyunsaturated fatty acids; SFA—saturated fatty acids.

\subsection{High-Performance Liquid Chromatography with Diode Array Detector (HPLC-DAD) Quantification of the Main Pentacyclic Triterpenes in the Leaves of Vaccinium Species}

In order to obtain more precise data on the quantities of some main pentacyclic triterpenes in the leaves of the Vaccinium species, HPLC-DAD analyses were conducted. The estimated content of oleanolic acid, ursolic acid, lupeol and $\alpha$-amyrin in the leaves of the populations of berry species varied significantly (Table 3). V. corymbosum var. Elliott biosynthesized the highest amounts of oleanolic acid, ursolic acid and lupeol $(981.3 \pm 17.2 \mu \mathrm{g} / \mathrm{g}$ dry weight (DW), $1994.4 \pm 25.4 \mu \mathrm{g} / \mathrm{g}$ DW, and $331.1 \pm 5.8 \mu \mathrm{g} / \mathrm{g}$ DW, respectively) compared with the other varieties of the same species. V. corymbosum var. Bluecrop leaves accumulated nearly twice as much $\alpha$-amyrin $(182.7 \pm 3.6 \mu \mathrm{g} / \mathrm{g} \mathrm{DW})$ as the other two varieties. The leaves of $V$. uliginosum (population Vu2) synthesized the highest concentrations of oleanolic and ursolic acid $(440.3 \pm 7.1 \mu \mathrm{g} / \mathrm{g}$ DW and $1201.3 \pm 19.2 \mu \mathrm{g} / \mathrm{g} \mathrm{DW}$, respectively) compared to the other two populations of the same species. The highest quantity of lupeol $(319.6 \pm 5.6 \mu \mathrm{g} / \mathrm{g}$ DW) was determined in the leaves of population Vu1. $\alpha$-amyrin was not detected only in the leaves of $V$. uliginosum populations. The highest amount of oleanolic acid, ursolic acid and lupeol in bilberry populations was found in Vm4 (from Mount Perelik), with $\alpha$-amyrin dominating in Vm1 (from Hut Ambaritza). The highest concentration of oleanolic acid in lingonberry populations was defined in Vi1 (from Mount Perelik at altitude $1930 \mathrm{~m}$ ), ursolic acid and lupeol being the dominant triterpenes in Vi5 (from locality Beklemeto). The leaves of population Vi7 (from Mount Perelik at altitude $1970 \mathrm{~m}$ ) accumulated the highest quantity of $\alpha$-amyrin.

Table 3. High-performance liquid chromatography with diode array detector (HPLC-DAD) analysis of the main pentacyclic triterpenes in the leaves of berry species.

\begin{tabular}{|c|c|c|c|c|}
\hline Sample, Abbreviation & $\begin{array}{c}\text { Oleanolic Acid, } \mu \mathrm{g} / \mathrm{g} \\
\text { DW }\end{array}$ & $\begin{array}{c}\text { Ursolic Acid, } \\
\mu \mathrm{g} / \mathrm{g} \text { DW }\end{array}$ & $\begin{array}{l}\text { Lupeol, } \\
\mu \mathrm{g} / \mathrm{g} \text { DW }\end{array}$ & $\begin{array}{l}\alpha \text {-Amyrin, } \\
\mu \mathrm{g} / \mathrm{g} \text { DW }\end{array}$ \\
\hline V. corymbosum var. Bluegold, (Vc1) & $735.5 \pm 13.6$ & $1102.5 \pm 19.3$ & $156.9 \pm 2.6$ & $91.7 \pm 1.9$ \\
\hline V. corymbosum var. Bluecrop, (Vc2) & $546.4 \pm 10.1$ & $1036.3 \pm 18.7$ & $73.8 \pm 1.2$ & $182.7 \pm 3.6$ \\
\hline V. corymbosum var. Elliott, (Vc3) & $981.3 \pm 17.2$ & $1994.4 \pm 25.4$ & $331.1 \pm 5.8$ & $84.6 \pm 1.9$ \\
\hline V. uliginosum, (Vu1) & $271.4 \pm 4.3$ & $1027.9 \pm 18.1$ & $319.6 \pm 5.6$ & 0 \\
\hline V. uliginosum, (Vu2) & $440.3 \pm 7.1$ & $1201.3 \pm 19.2$ & $236.5 \pm 4.1$ & 0 \\
\hline V. uliginosum, (Vu3) & $310.6 \pm 6.4$ & $845.3 \pm 15.4$ & $288.2 \pm 4.3$ & 0 \\
\hline V. myrtilus, (Vm1) & $505.2 \pm 10.6$ & $424.9 \pm 8.5$ & $20.9 \pm 0.8$ & $568.2 \pm 10.2$ \\
\hline V. myrtilus, (Vm2) & $335.2 \pm 6.8$ & $377.9 \pm 6.1$ & $20.0 \pm 0.8$ & $424.8 \pm 8.4$ \\
\hline V. myrtilus, (Vm3) & $643.1 \pm 12.2$ & $606.2 \pm 12.4$ & $21.1 \pm 0.7$ & $102.8 \pm 2.1$ \\
\hline V. myrtilus, (Vm4) & $655.8 \pm 10.1$ & $815.9 \pm 15.5$ & $55.9 \pm 1.4$ & $145.0 \pm 2.5$ \\
\hline V. myrtilus, (Vm5) & $573.8 \pm 9.3$ & $537.0 \pm 10.7$ & $35.3 \pm 1.1$ & $463.0 \pm 12.6$ \\
\hline V. vitis-idaea, (Vi1) & $488.7 \pm 8.7$ & $545.5 \pm 10.3$ & $432.9 \pm 8.2$ & $909.1 \pm 17.6$ \\
\hline V. vitis-idaea, (Vi2) & $236.8 \pm 4.5$ & $902.5 \pm 17.8$ & $300.5 \pm 6.4$ & $345.2 \pm 7.4$ \\
\hline V. vitis-idaea, (Vi3) & $262.4 \pm 4.1$ & $880.5 \pm 15.3$ & $604.3 \pm 12.1$ & $273.2 \pm 6.1$ \\
\hline V. vitis-idaea, (Vi4) & $252.1 \pm 4.9$ & $666.7 \pm 12.4$ & $769.2 \pm 14.6$ & $256.5 \pm 5.7$ \\
\hline V. vitis-idaea, (Vi5) & $355.9 \pm 6.7$ & $1240.2 \pm 21.5$ & $810.2 \pm 16.3$ & $494.1 \pm 12.4$ \\
\hline V. vitis-idaea, (Vi6) & $202.8 \pm 4.8$ & $629.1 \pm 12.6$ & $802.5 \pm 16.8$ & $377.9 \pm 6.8$ \\
\hline V. vitis-idaea, (Vi7) & $357.3 \pm 6.6$ & $355.3 \pm 5.9$ & $333.2 \pm 5.1$ & $1057.9 \pm 19.7$ \\
\hline
\end{tabular}




\subsection{Principal Component Analysis (PCA) and Hierarchical Cluster Analysis (HCA) of} GC-MS Data

In order to establish the differences between the metabolites identified in the berry species, PCA was conducted. According to the resulting PCA plot, the first two principal components PC1 $(27.1 \%)$ and PC2 (16.9\%) accounted for $44 \%$ of the total variance of all identified compounds in the leaves of the four Vaccinium species (Figure 1A). Metabolites with high positive scores in PC1 were benzoic acid, 4-methoxy-cinnamic acid, caprylic acid, palmitoleic acid, palmitelaidic acid, $\beta$ - sitosterol, squalene, phytol isomer, $\boldsymbol{n}$-hentriacontane, and pentacosylic acid that distinguished $V$. myrtillus and $V$. vitis-idaea from the other two species (V. corymbosum and V. uliginosum), (Figure 1B). Behenic acid, $\alpha$-linolenic acid, lignoceric acid, $\boldsymbol{n}$-tetracosanol, ceryl alcohol, octacosyl alcohol, capric acid, and cerotic acid showed high negative load scores in PC1 that distinguished V. corymbosum from the other three species (Figure 1B). V. uliginosum appeared clearly different from the other berry species by the high negative loadings values of $n$-eicosanol, arachidic acid, cycloartenol, 2 -tridecanone, $\boldsymbol{n}$-heneicosanol, linoleic acid, and lauric acid in PC2. The positive high scores of $n$-octanol, cycloartenyl acetate, oleic acid, lanosterol, $\beta$-amyrin, $\alpha$-amyrin and lupeol, lupenyl acetate, betulin and lupadienol acetate clearly distinguished V. vitis-idaea from the other three berry species. Stigmasterol and 4-hydroxybenzoic acid had high positive loadings values in PC2 and differentiated V. myrtillus from the other species.

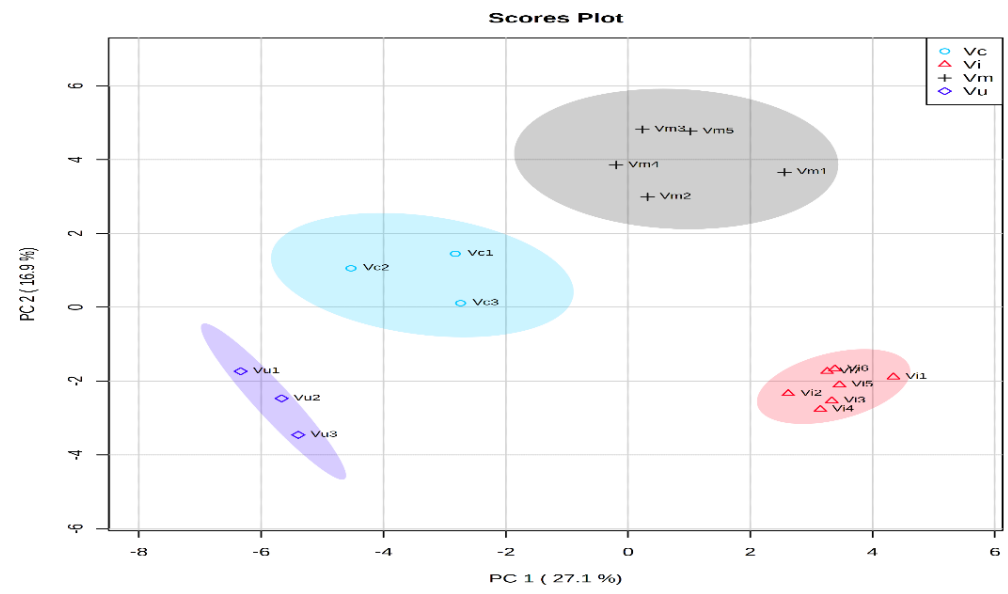

(A)

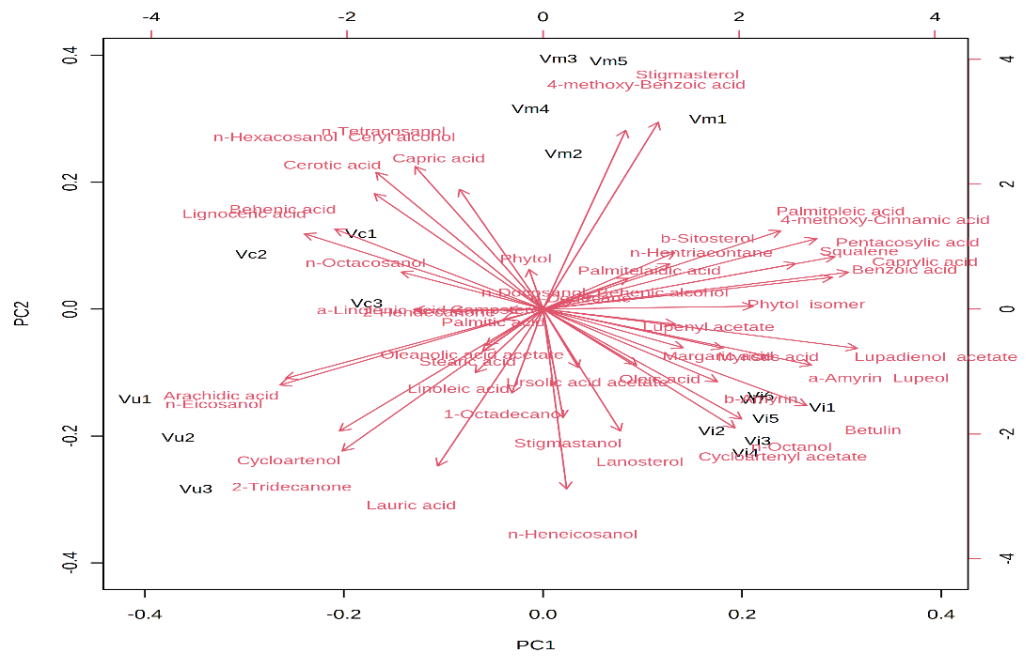

(B)

Figure 1. Principal component analysis (PCA) of GC-MS data of metabolites in the leaves of Vaccinium species. (A) Principal component score plot for the four Vaccinium species. (B) Eigenvector load values of compounds identified in the four Vaccinium species. 
The PCA results showed that the different populations of each berry species are relatively similar to each other and each formed a separate cluster, but the type and the relative amount of identified compounds differed among the diverse species investigated.

HCA was performed to outline the relationships among the eighteen berry samples (Figures 2 and 3). According to the dendrogram and heatmap obtained, the cultivated populations of $V$. corymbosum had the highest phytochemical similarity to the wild-growing populations of V. uliginosum and were grouped in one cluster. Wild-growing populations of $V$. myrtillus had the highest similarity to the naturally growing populations of $V$. vitis-idaea and were clustered together. The observed clusters can be explained with the higher relative content of fatty acids and lower relative amount of phythosterols and triterpenes in the leaves of $V$. corymbosum and $V$. uliginosum than in the leaves of $V$. myrtillus and $V$. vitis-idaea populations.

HCA also revealed that the V. corymbosum var. Bluegold had higher phytochemical similarity to $V$. corymbosum var. Bluecrop than with $V$. corymbosum var. Elliott and were grouped in one cluster. This differentiation was observed because of the higher relative content of fatty acids and phythosterols and significantly lower relative amount of triterpenes in the varieties Bluegold and Bluecrop than the variety Elliott.

The dendrogram and the heatmap also showed that the blueberry population Vu2 had higher phytochemical similarity to population $\mathrm{Vu} 3$ and were grouped in one cluster. Population Vu1 was in a separate cluster due to the lower relative content of fatty acids and higher relative quantity of triterpenes than the other two populations.

The five bilberry populations were grouped in three clusters, with the highest phytochemical distinction observed between populations Vm2 and Vm5. This differentiation was due to the higher relative content of fatty acids and triterpenes, and the significantly lower relative amount of fatty alcohols and phytosterols in the leaves of Vm2 than in the leaves of Vm5. Population Vm2 had the highest phytochemical similarity to Vm4, Vm1 possessing the closest resemblance to population $\mathrm{Vm} 5$.

According to the dendrogram and heatmap, the lingonberry populations differed significantly from each other and were grouped in five clusters. The highest phytochemical difference was observed in populations Vi2 andVi7, with Vi3 and Vi5 and Vi6 and Vi7 grouped in two clusters, respectively.

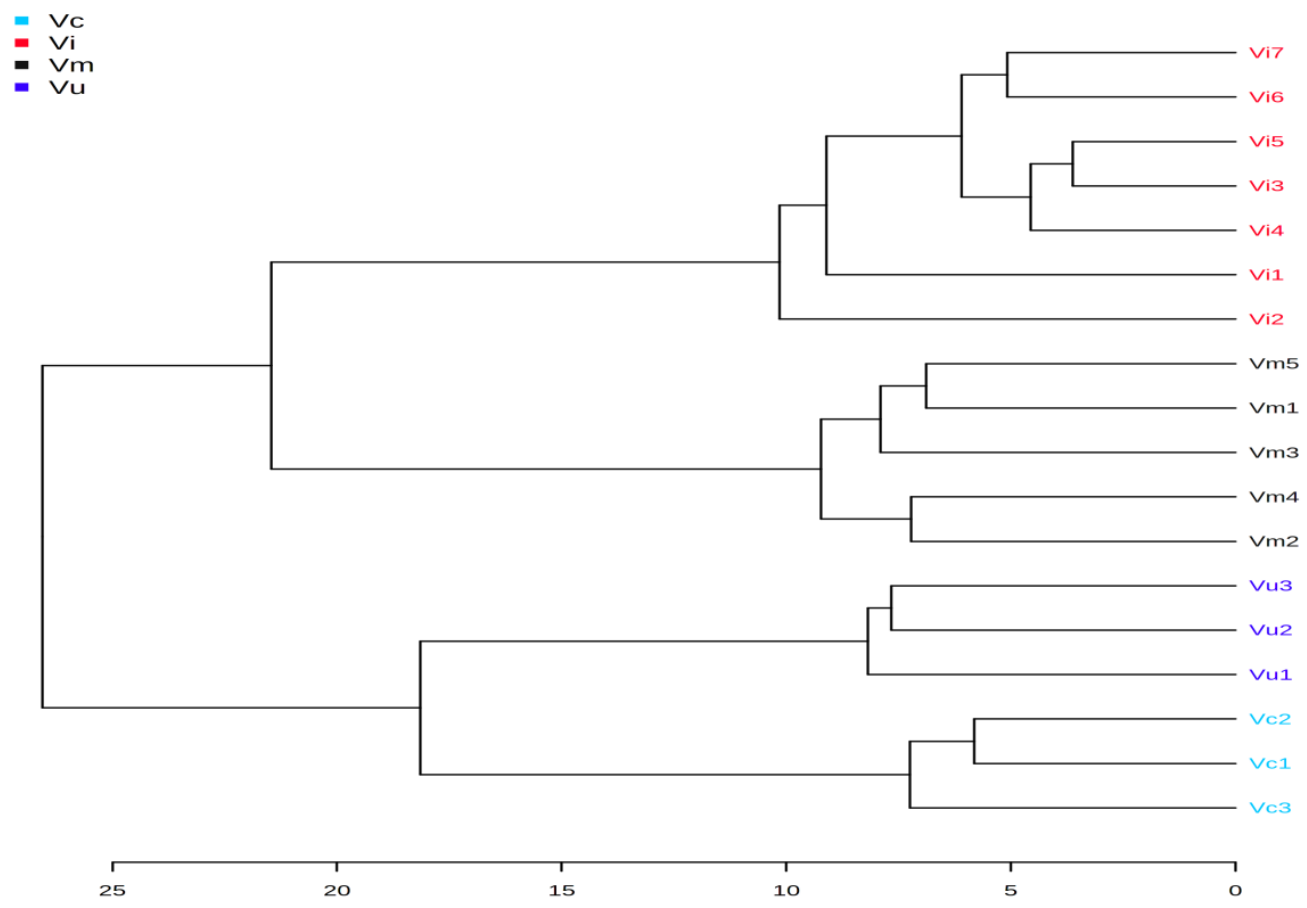

Figure 2. Clustering result of berry species, shown as dendrogram (by Euclidean distance measure, and Ward's clustering algorithm). 


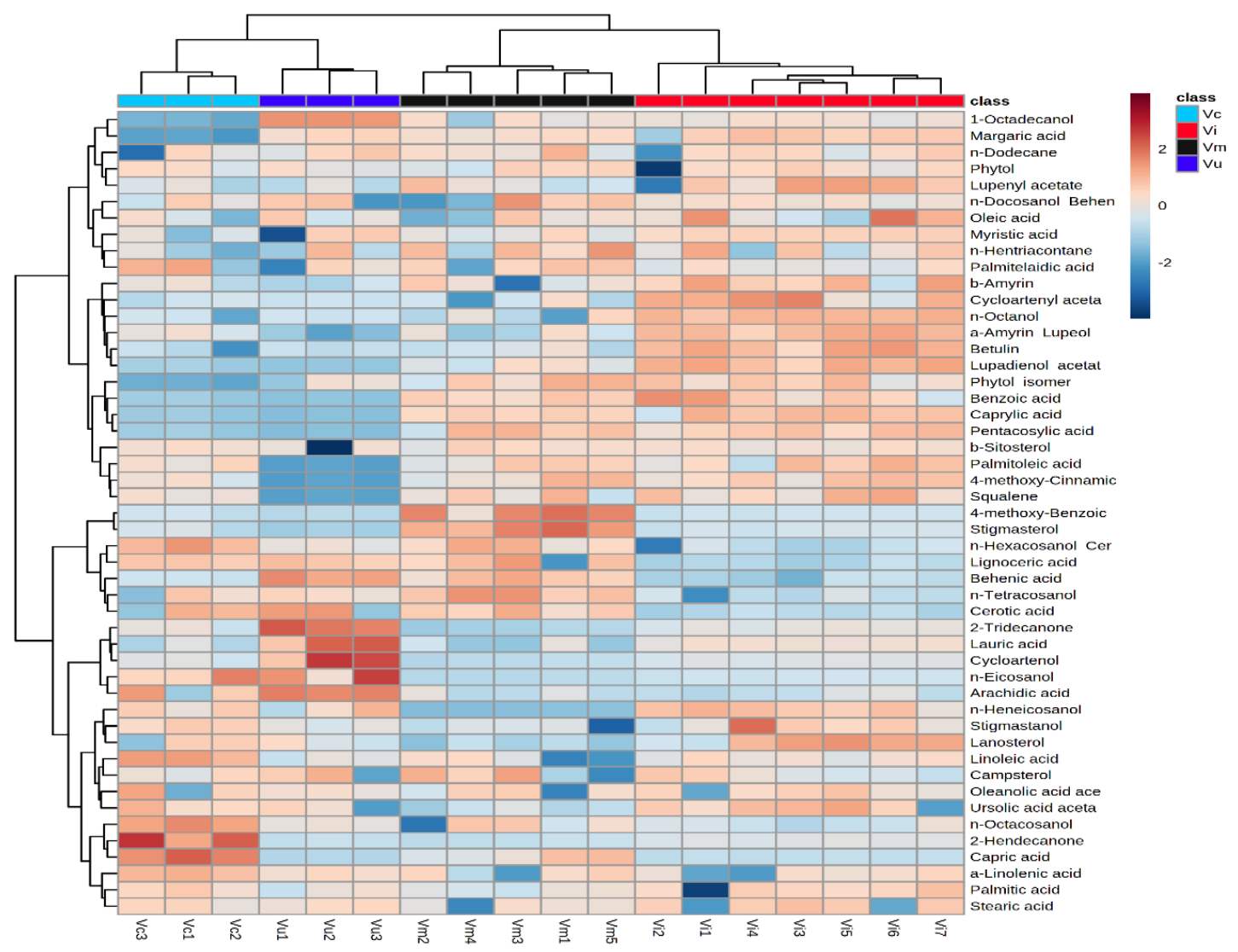

Figure 3. Clustering result of berry species, shown as heatmap. The color scale of the heat map ranged from dark brown (value, +2 ) to dark blue (value, -2 ). The values were normalized by log10 transformation.

\section{Discussion}

Metabolite profiling of different plant organs provides information on their chemical composition, allows detection of chemically diverse bioactive molecules and unknown compounds, as well as functional information on the metabolic phenotypes of plants [21,22]. The production of particular plant metabolites is a species-specific capability, strongly influenced by climatic and geographical conditions, growth phase, harvest time, post-harvest factors, biotic and abiotic stresses [23,24]. In this context, GC-MS analysis of non-polar leaf compounds of cultivated and naturally growing populations of berry species was conducted. The data obtained and the PCA and HCA performed in the current study showed that metabolite profiles differed significantly among the analyzed Vaccinium species, as well as among the populations of the same species naturally growing in different environmental conditions (Tables 1-3, Figures 1-3). The observed variations are in agreement with other investigations of berry species. Szakiel et al., 2012 [3] reported that the leaves of wild-growing V. myrtillus in distinct localities in Finland and Poland possessed significant differences in the triterpenoid content, with lupeol being much more abundant in Polish leaves, while the triterpene ketone, friedelin, was found exclusively in the leaves of Finnish plants, and taraxasterol was detected only in Polish plants. The contents of oleanolic and ursolic acids were similar in Finnish and Polish leaves, but the levels of $2 \alpha$-hydroxyoleanolic and $2 \alpha$-hydroxyursolic acids were more than 3 -fold higher in the latter [3].

Significant differences have also been established in young and old leaves of wildgrowing Finnish and Polish populations of $V$. vitis-idaea [2]. Neutral triterpenes were present in much higher amounts in leaves of Finnish than Polish plants, especially in young leaves collected in August (6-fold higher level). The most abundant compound of 
this class in Finnish leaves was fernenol (36\% and 32\% of this fraction in young and old leaves, respectively), which was found in only very small amounts in Polish leaves. The predominant triterpenol in Polish leaves was taraxasterol (32\% and $43 \%$ of this fraction in young and old leaves, respectively), which in turn occurred in small amounts in Finnish leaves [2].

Linoleic acid (18:2), $\alpha$-linolenic acid (18:3) and palmitic acid (16:0) were also the major fatty acids in wild-growing lingonberry and bilberry leaves in Poland. [25].

Moreover, the berry species studied here showed a high content of fatty acids (from C8 to C26) in the $\boldsymbol{n}$-hexane extracts obtained from the leaves. Cultivated blueberries $(V$. corymbosum) biosynthesized the highest concentrations of fatty acids, mainly $\alpha$-linolenic acid, which is an omega-3 polyunsaturated fatty acid and is essential for humans. The P:S ratio of cultivated blueberries was the highest $(2.09 \pm 0.11)$ compared to the wildgrowing populations of the species $V$. myrtillus $(1.08 \pm 0.28), V$. vitis-idea $(0.70 \pm 0.16)$ and $V$. uliginosum $(0.52 \pm 0.11)$. This is an important result that shows the potential use of the extracts from the leaves of cultivated blueberries as sources of essential fatty acids. Similar high concentrations of unsaturated fatty acids in the fruits of cultivated blueberries (V. corymbosum var. Patriot; var. North blue; var. Duke; var. Chippewa; var. Blue ray; Blue gold and var. Blue crop) were observed in samples of Latvian origin compared to fruits of wild-growing berries. The high content of unsaturated fatty acids can be defined as a chemotaxonomic marker of the species V. corymbosum [18].

The main triterpenoids ( $\beta$-amyrin, $\alpha$-amyrin, lupeol, oleanolic acid and ursolic acid) and the main phytosterol- $\beta$-sitosterol in the leaves of $V$. uliginosum, $V$. myrtillus, $V$. vitis-idaea identified in the current investigation (Tables 1 and 3) were also in higher concentrations compared with those in plants of Finnish, Polish, Latvian and Chilean populations of the same species [2,3,18,26-28].

Triterpenes are part of the plant defense system against different external and internal factors and have an important role in plant metabolism as regulators of the cell processes [2,3,29]. Ursolic, oleanolic acids, lupeol and amyrins are also the main triterpenoids of many fruit species, such as tomato, pepper, orange, grapes [30-33]. These components are found mainly in the fruit cuticle wax, but similar compounds have also been found in the flowers and leaves waxes of edible honeysuckle (Lonicera caerulea var. Kamtschatica) and common heather (Calluna vulgaris, Ericaceae) $[33,34]$. The wax in fruit and leaf cuticles are viewed as being relatively impermeable to gases including water vapor and existing as a cluster of crystalline waxes (mainly $\boldsymbol{n}$-alkanes, $\boldsymbol{n}$-alcohols, and fatty acids), both covering and embedded in a matrix of amorphous material (mostly triterpenoids and phytosterols). Water diffusion is considered to occur mostly in the amorphous fraction, while the crystalline cover would prevent further water transport [33,35]. Thus, the established high triterpenes concentration in the analyzed berry population (Tables 1 and 3) could be explained with the necessity of regulation and protection against various biotic and abiotic stresses. Moreover, ursolic acids and related pentacyclic triterpenoids (oleanolic acids, lupeol, $\alpha$-amyrin and $\beta$-amyrin) have been reported to possess various valuable biological activities, such as antioxidant, anticancer, anti-HIV, antiulcer, antiinflammatory, antimicrobial, gastroprotective, hepatoprotective, among others [36,37]. The main identified phytosterol- $\beta$-sitosterol also revealed diverse bioactivities, such as antidiabetic, chemoprotective, chemopreventive, hypocholesterolemic, anticancer, angiogenic and others [38]. These valuable biological activities are a prerequisite for the potential embedding of berry terpenes and phytosterols in different functional foods, food additives and pharmaceutical products. Furthermore, there is a growing tendency to use agricultural waste resources to produce high-value compounds. Vaccinium leaves and stems are considered essentially an agro-waste of the berry industry [39]. 


\section{Materials and Methods}

\subsection{Plant material}

The leaves of the. V. corymbosum (var. Bluegold, var. Bluecrop and var. Elliott), $V$. uliginosum, $V$. myrtillus and $V$. vitis-idaea samples were collected at the same developmental stages before flowering from different localities in Bulgaria, described in Table 4.

Table 4. Locations of V. corymbosum (var. Bluegold, var. Bluecrop and var. Elliott), V. uliginosum, V. myrtillus and V. vitis-idaea samples.

\begin{tabular}{|c|c|c|c|c|c|c|}
\hline Sample & ABBREVIATION & Location & Altitude, m & Slope & $\begin{array}{c}\text { Date of } \\
\text { Collection }\end{array}$ & Site \\
\hline $\begin{array}{l}\text { V. corymbosum } \\
\text { var. Bluegold }\end{array}$ & Vc1 & $\begin{array}{l}42^{\circ} 18^{\prime} 48.2^{\prime \prime} \mathrm{N} \\
23^{\circ} 32^{\prime} 31.1^{\prime \prime} \mathrm{E}\end{array}$ & 986 & $\mathrm{~N} / \mathrm{NE}$ & 4 June 2015 & $\begin{array}{c}\text { Municipal Forestry } \\
\text { Samokov, Rila Mountain }\end{array}$ \\
\hline $\begin{array}{l}V . \text { corymbosum } \\
\text { var. Bluecrop }\end{array}$ & $\mathrm{Vc} 2$ & $\begin{array}{l}42^{\circ} 18^{\prime} 48.2^{\prime \prime} \mathrm{N} \\
23^{\circ} 32^{\prime} 31.1^{\prime \prime} \mathrm{E}\end{array}$ & 986 & $\mathrm{~N} / \mathrm{NE}$ & 4 June 2015 & $\begin{array}{c}\text { Municipal Forestry } \\
\text { Samokov, Rila } \\
\text { Mountains }\end{array}$ \\
\hline $\begin{array}{l}\text { V. corymbosum } \\
\text { var. Bluecrop }\end{array}$ & $\mathrm{Vc} 3$ & $\begin{array}{l}42^{\circ} 18^{\prime} 48.2^{\prime \prime} \mathrm{N} \\
23^{\circ} 32^{\prime} 31.1^{\prime \prime} \mathrm{E}\end{array}$ & 986 & $\mathrm{~N} / \mathrm{NE}$ & 4 June 2015 & $\begin{array}{c}\text { Municipal Forestry } \\
\text { Samokov, Rila Mountain }\end{array}$ \\
\hline V. uliginosum & Vu1 & $\begin{array}{l}41^{\circ} 36^{\prime} 30.5^{\prime \prime} \mathrm{N} \\
24^{\circ} 35^{\prime} 49.8^{\prime \prime} \mathrm{E}\end{array}$ & 1930 & N/NW & 31 May 2015 & $\begin{array}{l}\text { Mount Golyam Perelik, } \\
\text { Rhodope Mountains }\end{array}$ \\
\hline V. uliginosum & $\mathrm{Vu} 2$ & $\begin{array}{l}42^{\circ} 34^{\prime} 46.0^{\prime \prime} \mathrm{N} \\
23^{\circ} 17^{\prime} 26.2^{\prime \prime} \mathrm{E}\end{array}$ & 1950 & $\mathrm{~N} / \mathrm{NE}$ & 8 June 2015 & $\begin{array}{l}\text { Aleko Hut, Cherni Vryh } \\
\text { path, Vitosha Mountain }\end{array}$ \\
\hline V. uliginosum & Vu3 & $\begin{array}{l}42^{\circ} 46^{\prime} 52.4^{\prime \prime} \mathrm{N} \\
24^{\circ} 37^{\prime} 21.3^{\prime \prime} \mathrm{E}\end{array}$ & 1460 & $\mathrm{~N} / \mathrm{NE}$ & 30 May 2015 & $\begin{array}{l}\text { Beklemeto, Balkan } \\
\text { Mountains }\end{array}$ \\
\hline V. myrtillus & Vm1 & $\begin{array}{l}42^{\circ} 45^{\prime} 18.1^{\prime \prime} \mathrm{N} \\
24^{\circ} 46^{\prime} 43.3^{\prime \prime} \mathrm{E}\end{array}$ & 1510 & $\mathrm{~N} / \mathrm{NE}$ & 12 June 2015 & $\begin{array}{c}\text { Ambaritsa Hut, Balkan } \\
\text { Mountains }\end{array}$ \\
\hline V. myrtillus & $\mathrm{Vm} 2$ & $\begin{array}{l}42^{\circ} 13^{\prime} 53.6^{\prime \prime} \mathrm{N} \\
23^{\circ} 35^{\prime} 24.6^{\prime \prime} \mathrm{E}\end{array}$ & 1740 & $\mathrm{~N} / \mathrm{NE}$ & 3 June 2015 & $\begin{array}{l}\text { Borovets, Musala path, } \\
\text { Rila Mountain }\end{array}$ \\
\hline V. myrtillus & $\mathrm{Vm} 3$ & $\begin{array}{l}41^{\circ} 38^{\prime} 40.6^{\prime \prime} \mathrm{N} \\
24^{\circ} 33^{\prime} 23.4^{\prime \prime} \mathrm{E}\end{array}$ & 1660 & $\mathrm{~N} / \mathrm{NE}$ & 1 June 2015 & $\begin{array}{l}\text { St Marina chapel(near } \\
\text { Gela), Rhodope } \\
\text { Mountains }\end{array}$ \\
\hline V. myrtillus & $\mathrm{Vm} 4$ & $\begin{array}{l}41^{\circ} 36^{\prime} 30.5^{\prime \prime} \mathrm{N} \\
24^{\circ} 35^{\prime} 49.8^{\prime \prime} \mathrm{E}\end{array}$ & 1930 & N/NW & 31 May 2015 & $\begin{array}{l}\text { Mount Golyam Perelik, } \\
\text { Rhodope Mountains }\end{array}$ \\
\hline V. myrtillus & Vm5 & $\begin{array}{l}42^{\circ} 46^{\prime} 27.6^{\prime \prime} \mathrm{N} \\
24^{\circ} 37^{\prime} 00.0^{\prime \prime} \mathrm{E}\end{array}$ & 1470 & $\mathrm{~N} / \mathrm{NE}$ & 30 May 2015 & $\begin{array}{l}\text { Beklemeto, Balkan } \\
\text { Mountains }\end{array}$ \\
\hline V. vitis-idaea & Vi1 & $\begin{array}{l}41^{\circ} 36^{\prime} 30.5^{\prime \prime} \mathrm{N} \\
24^{\circ} 35^{\prime} 49.8^{\prime \prime} \mathrm{E}\end{array}$ & 1930 & N/NW & 31 May 2015 & $\begin{array}{l}\text { Mount Golyam Perelik, } \\
\text { Rhodope Mountains }\end{array}$ \\
\hline V. vitis-idaea & Vi2 & $\begin{array}{l}42^{\circ} 34^{\prime} 46.0^{\prime \prime} \mathrm{N} \\
24^{\circ} 17^{\prime} 24.2^{\prime \prime} \mathrm{E}\end{array}$ & 2060 & $\mathrm{~N} / \mathrm{NE}$ & 8 June 2015 & $\begin{array}{l}\text { Aleko Hut, Cherni Vryh } \\
\text { path, Vitosha Mountain }\end{array}$ \\
\hline V. vitis-idaea & Vi3 & $\begin{array}{l}42^{\circ} 13^{\prime} 53.6^{\prime \prime} \mathrm{N} \\
23^{\circ} 35^{\prime} 24.6^{\prime \prime} \mathrm{E}\end{array}$ & 1740 & $\mathrm{~N} / \mathrm{NE}$ & 3 June 2015 & $\begin{array}{l}\text { Borovets, Musala path, } \\
\text { Rila Mountain }\end{array}$ \\
\hline V. vitis-idaea & Vi4 & $\begin{array}{l}41^{\circ} 37^{\prime} 58.0^{\prime \prime} \mathrm{N} \\
24^{\circ} 33^{\prime} 11.0^{\prime \prime} \mathrm{E}\end{array}$ & 1780 & $\mathrm{~N} / \mathrm{NE}$ & 1 June 2015 & $\begin{array}{c}\text { near Gradishte Thracian } \\
\text { fortress, Rhodope } \\
\text { Mountains }\end{array}$ \\
\hline V. vitis-idaea & Vi5 & $\begin{array}{l}42^{\circ} 46^{\prime} 27.6^{\prime \prime} \mathrm{N} \\
24^{\circ} 37^{\prime} 00.0^{\prime \prime} \mathrm{E}\end{array}$ & 1470 & $\mathrm{~N} / \mathrm{NE}$ & 30 May 2015 & $\begin{array}{l}\text { Beklemeto, Balkan } \\
\text { Mountains }\end{array}$ \\
\hline V. vitis-idaea & Vi6 & $\begin{array}{l}42^{\circ} 52^{\prime} 45.2^{\prime \prime} \mathrm{N} \\
24^{\circ} 28^{\prime} 58.1^{\prime \prime} \mathrm{E}\end{array}$ & 1360 & $\mathrm{~N} / \mathrm{NE}$ & 11 June 2015 & $\begin{array}{c}\text { Vasilyov Hut, Balkan } \\
\text { Mountains }\end{array}$ \\
\hline V. vitis-idaea & Vi7 & $\begin{array}{l}41^{\circ} 36^{\prime} 24.0^{\prime \prime} \mathrm{N} \\
24^{\circ} 35^{\prime} 48.3^{\prime \prime} \mathrm{E}\end{array}$ & 1970 & $\mathrm{~N} / \mathrm{NE}$ & 31 May 2015 & $\begin{array}{l}\text { Mount Golyam Perelik, } \\
\text { Rhodope Mountains }\end{array}$ \\
\hline
\end{tabular}

\subsection{Extraction Procedure}

The collected leaf samples were lyophilized and ground using an electric mill (Tissue Lyser II, Qiagen) with frequency $30.0(1 / \mathrm{s})$ at $22{ }^{\circ} \mathrm{C}$ for $1 \mathrm{~min}$ (three times for $20 \mathrm{~s}$ each). Each sample (in triplicate) was extracted twice with acetone (hydro module $1: 20, \mathrm{~m} / \mathrm{v}$ ) at room temperature for $24 \mathrm{~h}$, according to the method described by Ivanov et al., 2019 [40]. The combined extracts were evaporated to dryness at $40^{\circ} \mathrm{C}$ under vacuum and subjected to alkaline hydrolysis with $2 \mathrm{~mol} / \mathrm{L} \mathrm{KOH}$ (dissolved in $50 \%$ ethanol) in water bath at $80^{\circ} \mathrm{C}$ 
under reflux heat for $1.5 \mathrm{~h}$. After cooling, the extracts were neutralized to $\mathrm{pH} 7$ with HCL and separated by liquid-liquid extraction with $\boldsymbol{n}$-hexane. The $\boldsymbol{n}$-hexane fractions were evaporated to dryness and used for HPLC-DAD and GC-MS analyses.

\subsection{GC-MS Analyses and Identification of Compounds}

We added 100.0 $\mu \mathrm{L}$ pyridine and 100.0 $\mu \mathrm{L}$ N,O-Bis(trimethylsilyl)trifluoroacetamide (BSTFA) to the dried residue of extracts, then heated on Thermoshaker (Analytik Jena AG, Germany) at $70{ }^{\circ} \mathrm{C}$ and $300 \mathrm{rpm}$ for $45 \mathrm{~min}$.

GC-MS analyses were carried out on a 7890A gas chromatograph, interfaced with a mass selective detector 5975C Agilent Technology 5975C inert XL EI/CI MSD (Agilent, USA). Separation of compounds was performed using a DB-5ms silica-fused capillary column $(30 \mathrm{~m} \times 0.25 \mathrm{~mm} \times 0.25 \mu \mathrm{m})$ coated with $0.25 \mu \mathrm{m}$ film of polydimethylsiloxane as the stationary phase. The oven temperature program was: initial temperature $100^{\circ} \mathrm{C}$, hold for $2 \mathrm{~min}$, then raise to $180{ }^{\circ} \mathrm{C}$ by temperature increments of $15^{\circ} \mathrm{C} / \mathrm{min}$, hold at $180{ }^{\circ} \mathrm{C}$ for $1 \mathrm{~min}$, then raise by temperature increments of $5^{\circ} \mathrm{C} / \mathrm{min}$ to $300{ }^{\circ} \mathrm{C}$, and hold for $10 \mathrm{~min}$. The flow rate of the carrier gas (helium) was maintained at $1.0 \mathrm{~mL} / \mathrm{min}$. The injector and the transfer line temperature were kept at $250{ }^{\circ} \mathrm{C}$. The injection volume was $1 \mu \mathrm{L}$ in split mode 20:1. All mass spectra were acquired in an electron impact (EI) mode with $70 \mathrm{eV}$ over a mass range of $\mathrm{m} / \mathrm{z}=50-550$.

The mass spectra were read using AMDIS software, version 2.64 (Automated Mass Spectral Deconvolution and Identification System, National Institute of Standardization and Technology (NIST), Gaithersburg, MD, USA). A mixture of aliphatic hydrocarbons $\mathrm{C}_{8}-\mathrm{C}_{40}$ (Sigma) was injected into the system under the above temperature program in order to calculate the retention index (RI) of each compound. The compounds were identified by comparison of their GC-MS spectra and Kovats retention index (RI) with reference compounds in the Golm Metabolome Database [41] and NIST'08 data base (NIST Mass Spectral Database, PC-Version 5.0, 2008 from the National Institute of Standards and Technology, Gaithersburg, MD, USA). The results were presented as \% of total ion current (\% of TIC).

\subsection{HPLC-DAD Analysis}

The dried extracts were dissolved in methanol (Sigma-Aldrich Chemie GmbH, Darmstadt, Germany). Chromatographic separation and determination of triterpene content was performed on a Hitachi LaChrom Elite ${ }^{\circledR}$ HPLC System (Hitachi High Technologies America, Inc., Schaumburg, Illinois, USA), coupled with diode-array detector (DAD, L-2455) and EZChrom Elite ${ }^{\mathrm{TM}}$ software. The separation of oleanolic and ursolic acid (Extrasynthese, Lyon, France) was performed on a reverse-phase column Supelco, Discovery ${ }^{\circledR}$ HS C18 $(5 \mu \mathrm{m}, 25 \mathrm{~cm} \times 4.6 \mathrm{~mm})$ operating at $26^{\circ} \mathrm{C}$. Elution was performed with a mobile phase consisted of methanol:0.1\% HCOOH = 92:8 (v/v), (Sigma-Aldrich Chemie GmbH, Darmstadt, Germany) in an isocratic mode with a flow rate $0.4 \mathrm{~mL} / \mathrm{min}$. The separation of lupeol and $\alpha$-amyrin (Extrasynthese, Lyon, France) was performed on a reverse-phase column Waters Spherisorb C8 $(5 \mu \mathrm{m}, 15 \mathrm{~cm} \times 4.6 \mathrm{~mm})$ operating at $26{ }^{\circ} \mathrm{C}$. Elution was performed with a mobile phase consisted of acetonitrile:0.1\% HCOOH = 92:8 (v/v), (Sigma-Aldrich Chemie $\mathrm{GmbH}$, Darmstadt Germany) in an isocratic mode with a flow rate $0.4 \mathrm{~mL} / \mathrm{min}$. Detection was carried out at wavelength $210 \mathrm{~nm}$ and the sample injection volume was $20 \mu \mathrm{L}$ for both methods.

\subsection{Statistical Analysis}

PCA and HCA of GC-MS data were conducted using MetaboAnalyst-a web-based platform (www.metaboanalyst.ca) [42]. Firstly, PCA was applied in order to calculate the eigenvector load values and to identify the major statistically different components among the observations (samples). The GC-MS data were mean-centered and the PCA model was obtained at a confidence level of $95 \%$. The GC-MS data were also subjected to HCA 
that produced a dendrogram by Ward's method of hierarchical clustering and Euclidean distance measurement between the analyzed samples.

\section{Conclusions}

To the best of our knowledge, this is the first report on metabolite profiling of triterpenes and other non-polar compounds in the leaves of cultivated (V. corymbosum var. Bluegold, var. Bluecrop and var. Elliott) and wild populations (V. uliginosum, V. myrtillus and $V$. vitis-idaea) of Vaccinium species growing in Bulgaria. Considering the presence of valuable triterpenes, phytosterols and fatty acids in the leaves of all investigated berry species, they could be used as potential raw materials for production of health foods, food ingredients, as well as active cosmetic ingredients. The established variations in the content of individual triterpenoids and other non-polar compounds among the investigated populations of the same species could be explained by the variations in the climatic and geographical conditions of their habitats. GC-MS based metabolite profiling and subsequent chemometric analyses, such as PCA and HCA, could be successfully applied for the metabolic chemotaxonomy of berry species, which is especially important for the food, pharmaceutical and cosmetic industries. Furthermore, plant material of these species should be analyzed and standardized to ensure that its quality is suitable for specific economic applications.

Author Contributions: Conceptualization, A.P. and I.I.; methodology, R.V., I.D. and I.B.; software, R.V.; formal analysis, R.V., I.D. and I.B.; resources, I.D. and I.B.; Writing-Original draft preparation, R.V. and I.I.; Writing—Review and Editing, A.P.; supervision, A.P.; project administration, A.P. All authors have read and agreed to the published version of the manuscript.

Funding: This research was funded by Bulgarian Science Fund, Bulgarian Ministry of Education and Science, grant number DN 16/1- 11.12.2017.

Institutional Review Board Statement: Not applicable.

Informed Consent Statement: Not applicable.

Data Availability Statement: Not applicable.

Conflicts of Interest: The authors declare no conflict of interest.

\section{References}

1. Karppinen, K.; Zoratti, L.; Nguyenquynh, N.; Häggman, H.; Jaakola, L. On the Developmental and Environmental Regulation of Secondary Metabolism in Vaccinium spp. Berries. Front. Plant Sci. 2016, 7, 655. [CrossRef]

2. Szakiel, A.; Pączkowski, C.; Koivuniemi, H.; Huttunen, S. Comparison of the triterpenoid content of berries and leaves of lingonberry Vaccinium vitis-idaea from Finland and Poland. J. Agric. Food Chem. 2012, 60, 4994-5002. [CrossRef] [PubMed]

3. Szakiel, A.; Pączkowski, C.; Koivuniemi, H.; Huttunen, S. Triterpenoid Content of Berries and Leaves of Bilberry Vaccinium myrtillus from Finland and Poland. J. Agric. Food Chem. 2012, 60, 11839-11849. [CrossRef] [PubMed]

4. Su, S.; Wang, L.J.; Wu, J.; Li, B.; Wang, W.W.; Wang, L.S. Review: Chemical compositions and functions of Vaccinium uliginosum. Chin. Bull. Bot. 2016, 51, 691-704.

5. Ștefănescu, B.E.; Szabo, K.; Mocan, A.; Crişan, G. Phenolic Compounds from Five Ericaceae Species Leaves and Their Related Bioavailability and Health Benefits. Molecules 2019, 24, 2046. [CrossRef]

6. Persson, I.A.-L.; Persson, K.; Andersson, R.G.G. Effect of Vaccinium myrtillus and its polyphenols on angiotensin-converting enzyme activity in human endothelial cells. J. Agric. Food Chem. 2009, 57, 4626-4629. [CrossRef]

7. Madvahi, D.L.; Bomser, J.; Smith, M.A.L.; Singletary, K. Isolation of bioactive constituents from Vaccinium myrtillus (bilberry) fruits and cell culture. Plant Sci. 1998, 131, 95-103.

8. Cignarella, A.; Nastasi, M.; Cavalli, E.; Puglisi, L. Novel lipid lowering properties of Vaccinium myrtillus L. leaves, a traditional antidiabetic treatment, in several models of rat dyslipidaemia: A comparison with ciprofibrate. Thromb. Res. 1996, 84, 311-322. [CrossRef]

9. Ieri, F.; Martini, S.; Innocenti, M.; Mulinacci, N. Phenolic distribution in liquid preparations of Vaccinium myrtillus L. and Vaccinium vitis idaea L. Phytochem. Anal. 2013, 24, 467-475. [CrossRef]

10. Riihinen, K.; Jaakola, L.; Karenlampi, S.; Hohtola, A. Organspecific distribution of phenolic compounds in bilberry (Vaccinium myrtillus) and 'northblue' blueberry (Vaccinium corymbosum $x$ V. angustifolium). Food Chem. 2008, 110, 156-160. [CrossRef]

11. Moze, S.; Polak, T.; Gasperlin, L.; Koron, D.; Vanzo, A.; Ulrih, N.P.; Abram, V. Phenolics in slovenian bilberries (Vaccinium myrtillus L.) and blueberries (Vaccinium corymbosum L.). J. Agric. Food Chem. 2011, 59, 6998-7004. 
12. Rimando, A.M.; Kalt, W.K.; Magee, J.B.; Dewey, J.; Ballington, J.R. Resveratrol, pterostilbene, and piceatannol in Vaccinium berries. J. Agric. Food Chem. 2004, 52, 4713-4719. [CrossRef] [PubMed]

13. Jensen, H.D.; Krogfelt, K.A.; Cornett, C.; Hansen, S.H.; Christensen, S.B. Hydrophilic carboxylic acids and iridoid glycosides in the juice of American and European cranberries (Vaccinium macrocarpon and V. oxycoccos), lingonberries (V. vitis-idaea), and blueberries (V. myrtillus). J. Agric. Food Chem. 2002, 50, 6871-6874. [CrossRef]

14. Wang, X.; Sun, H.; Fan, Y.; Li, L.; Makino, T.; Kano, Y. Analysis and bioactive evaluation of the compounds absorbed into blood after oral administration of the extracts of Vaccinium vitis-idaea in rat. Biol. Pharm. Bull. 2005, 28, 1106-1108. [CrossRef] [PubMed]

15. Szakiel, A.; Mroczek, A. Distribution of triterpene acids and their derivatives in organs of cowberry (Vaccinium vitis-idaea L.) plant. Acta Biochim. Pol. 2007, 54, 733-740.

16. Laslo, E.; Köbölkuti, Z. Total phenol content and antimicrobial activity of lingonberry (Vaccinium vitis-idaea L.) from several areas in the eastern Carpathians. Not. Sci. Biol. 2017, 9, 77-83. [CrossRef]

17. Kontiokari, T.; Nuutinen, M.; Uhari, M. Dietary factors affecting susceptibility to urinary tract infection. Pediatr. Nephrol. 2004, 19, 378-383. [CrossRef] [PubMed]

18. Klavins, L.; Viksna, A.; Kviesis, J.; Klavins, M. Lipid of cultivated and wild Vaccinium spp. berries from Latvia. FoodBalt 2019, 198-203. [CrossRef]

19. Migas, P.; Cisowski, W.; Dembińska-Migas, W. Isoprene derivatives from the leaves and callus cultures of Vaccinium corymbosum var. bluecrop. Acta Pol. Pharm. 2005, 62, 45-51.

20. Guo, Y.; Zhang, T.; Zhong, J.; Ba, T.; Xu, T.; Zhang, Q.; Sun, M. Identification of the Volatile Compounds and Observation of the Glandular Trichomes in Opisthopappus taihangensis and Four Species of Chrysanthemum. Plants 2020, 9, 855. [CrossRef]

21. Kopka, J. Current challenges and developments in GC-MS based metabolite profiling technology. J. Biotechnol. 2006, 124, 312-322. [CrossRef] [PubMed]

22. Torras-Claveria, L.; Berkov, S.; Jauregui, O.; Caujape, J.; Viladomat, F.; Codina, C.; Bastida, J. Metabolic profiling of bioactive Pancratium canariense extracts by GC-MS. Phytochem. Anal. 2010, 21, 80-88. [CrossRef] [PubMed]

23. Cevallos-Cevallos, J.M.; Futch, D.B.; Shilts, T.; Folimonova, S.Y.; Reyes-De-Corcuera, J.I. GC-MS metabolomics differentiation of selected citrus varieties with different sensitivity to citrus huanglongbing. Plant Physiol. Biochem. 2012, 53, 69-76. [CrossRef] [PubMed]

24. Keutgen, A.J.; Pawelzik, E. Quality and nutritional value of strawberry fruit under long term salt stress. Food Chem. 2008, 107, 1413-1420. [CrossRef]

25. Liu, P.; Lindstedt, A.; Markkinen, N.; Sinkkonen, J.; Suomela, J.P.; Yang, B. Characterization of metabolite profiles of leaves of bilberry (Vaccinium myrtillus L.) and lingonberry (Vaccinium vitis-idaea L.). J. Agric. Food Chem. 2014, 62, 12015-12026. [CrossRef]

26. Moggia, C.; Graell, J.; Lara, I.; Schmeda-Hirschmann, G.; Tomas-Valdes, S.; Lobos, G.A. Fruit characteristics and cuticle triterpenes as related to postharvest quality of highbush blueberries. Sci. Hortic. 2016, 211, 449-457. [CrossRef]

27. Klavins, L.; Klavina, L.; Huna, A.; Klavins, M. Polyphenols, carbohydrates and lipids in berries of Vaccinium species. Environ. Exp. Biol. 2015, 13, 147-158.

28. Dashbaldan, S.; Becker, R.; Paczkowski, C.; Szakiel, A. Various patterns of composition and accumulation of steroids and terpenoids in cuticular waxes from screened Ericaceae and Caprifoliaceae berries during fruit development. Molecules 2019, 24, 3826. [CrossRef]

29. Du Fall, L.A.; Solomon, P.S. Role of cereal secondary metabolites involved in mediating the outcome of plant-pathogen interactions. Metabolites 2011, 1, 64-78. [CrossRef]

30. Lara, I.; Belge, B.; Goulao, L.F. The fruit cuticle as a modulator of postharvest quality. Postharvest Biol. Technol. 2014, 87, 103-112. [CrossRef]

31. Cho, J.Y.; Kim, C.M.; Lee, H.J.; Lee, S.H.; Cho, J.A.; Kim, W.S.; Park, K.H.; Moon, J.H. Caffeoyl triterpenes from pear (Pyrus pyrifolia Nakai) fruit peels and their antioxidative activities against oxidation of rat blood plasma. J. Agric. Food Chem. 2013, 61, 4563-4569. [CrossRef]

32. Lara, I.; Belge, B.; Goulao, L. A focus on the biosynthesis and composition of cuticle in fruits. J. Agric. Food Chem. 2015, 63, 4005-4019. [CrossRef] [PubMed]

33. Szakiel, A.; Pączkowski, C.; Pensec, F.; Bertsch, C. Fruit cuticular waxes as a source of biologically active triterpenoids. Phytochem Rev. 2012, 11, 263-284. [CrossRef] [PubMed]

34. Becker, R.; Pączkowski, C.; Szakiel, A. Triterpenoid profile of fruit and leaf cuticular waxes of edible honeysuckle Lonicera caerulea var. kamtschatica. Acta Soc. Bot. Pol. 2017, 86, 3539. [CrossRef]

35. Vogg, G.; Fischer, S.; Leide, J.; Emmanuel, E.; Jetter, R.; Levy, A.A.; Riederer, M. Tomato fruit cuticular waxes and their effects on transpiration barrier properties: Functional characterization of a mutant deficient in a very-long-chain fatty acid beta-ketoacyl-CoA synthase. J. Exp. Bot. 2004, 55, 1401-1410. [CrossRef] [PubMed]

36. Novotny, L.; Vachalkova, A.; Biggs, D. Ursolic acid: An anti-tumorigenic and chemopreventive activity minireview. Neoplasma 2001, 48, 241-246.

37. Neto, C.C. Ursolic Acid and Other Pentacyclic Triterpenoids: Anticancer Activities and Occurrence in Berries. In Berries and Cancer Prevention; Stoner, G.D., Seeram, N.P., Eds.; Springer Science + Business Media, LLC: New York, NY, USA, 2011 ; pp. 41-49.

38. Saeidnia, S.; Manayi, A.; Gohari, A.R.; Abdollahi, M. The Story of Beta-sitosterol-A Review. Eur. J. Med. Plant 2014, 4, 590-609. [CrossRef] 
39. Bujor, O.C.; Tanase, C.; Popa, M.E. Phenolic Antioxidants in Aerial Parts of Wild Vaccinium Species: Towards Pharmaceutical and Biological Properties. Antioxidants 2019, 8, 649. [CrossRef]

40. Ivanov, I.; Dincheva, I.; Badjakov, I.; Petkova, N.; Denev, P.; Pavlov, A. GC-MS analysis of unpolar fraction from Ficus carica L. (fig) leaves. Int. Food Res. J. 2018, 25, 282-286.

41. Golm Metabolome Database. Available online: http://www.csbdb.mpimp-golm.mpg.de/csbdb/gmd/gmd.html (accessed on 9 March 2020).

42. MetaboAnalyst 4.0-Statistical, Functional and Integrative Analysis of Metabolomics Data. Available online: https://www. metaboanalyst.ca/MetaboAnalyst/ModuleView.xhtml (accessed on 2 November 2020). 